\title{
Innovative moments in grief therapy: The meaning reconstruction approach and the processes of self-narrative transformation
}

\author{
DANIELA ALVES ${ }^{1}$, PABLO FERNÁNDEZ-NAVARRO ${ }^{1}$, JOÃO BAPTISTA ${ }^{1}$, \\ EUGÉNIA RIBEIRO $^{1}$, INÊS SOUSA ${ }^{2}$, \& MIGUEL M. GONÇALVES ${ }^{1}$ \\ ${ }^{1}$ Psychology, University of Minho, Braga, Portugal $\mathcal{E}{ }^{2}$ Mathematics and Applications, University of Minho, Braga, Portugal
}

(Received 22 October 2012; revised 3 fune 2013; accepted 7 fune 2013)

\begin{abstract}
Several studies have proposed that self-narrative transformation occurs through the elaboration of "Innovative Moments" (IMs), which are alternative experiences to the problematic self-narrative. This study aimed to analyze the emergence of IMs among 6 complicated grief women undergoing grief therapy according to the meaning reconstruction approach and to examine associations of IMs to the severity of grief symptomatology, assessed by the "Inventory of Complicated Grief." Eighty-three sessions were analyzed using the "Innovative Moments Coding System" (IMCS). A generalized linear model analysis (GLM) showed a significant association between the emergence of IMs and the interaction between time and symptomatic improvement, indicating a higher rate of IM production over time in cases with better clinical outcomes. These results reinforce IMs' relevance in studying narrative change among cases with distinct clinical progressions.
\end{abstract}

Keywords: narrative change; innovative moments; innovative moments coding system; grief therapy; meaning reconstruction approach; process research

In the last decade, researchers have demonstrated an increased interest in how clients' self-narratives change across therapy (Angus \& McLeod, 2004; Gonçalves \& Stiles, 2011; Luborsky, Singer, \& Luborsky, 1975). This perspective on human change assumes that clients act as active storytellers and organize their multiple life experiences into coherent stories - or self-narratives - that they share with others (Angus \& McLeod, 2004; Bruner, 1990, 2004; Gonçalves, Matos, \& Santos, 2009; McAdams, 2001; Neimeyer, Herrero, \& Botella, 2006; Sarbin, 1986; White, 2007; White \& Epston, 1990). According to this narrative approach, self-narratives may become dysfunctional if they lack flexibility and start to exclude relevant experiences of person's life (see Dimaggio, 2006, for other narrative dysfunctions). That is, while the way persons experience the world may contribute to the construction of an inflexible narrative, this inflexible narrative, in turn, also has an impact on persons' experiences and interpretations. These specific interpretations can narrow people's understanding of themselves and the world, selecting which experiences are included and which are left out of the personã s self-narrative (Polkinghorne, 2004). In this sense, it influences the way the person interacts with the world (imposing certain rules that shape the person's meaning system, influencing behavior, thoughts, feelings and relationships).

According to Gonçalves and collaborators (2009), change in psychotherapy occurs as clients transform their previously inflexible or problematic self-narrative into a more functional one. According to these authors this transformation process depends on the emergence of alternative ways of experiencing to the ones imposed by the problematic self-narrative. Clients' expressions of these alternative ways of experiencing are referred to as "Innovative Moments."

To track the emergence and development of IMs, Gonçalves and collaborators (2009) developed the Innovative Moments Coding System (IMCS; Gonçalves, Ribeiro, Matos, Santos, \& Mendes, 2010; Gonçalves, Ribeiro, Mendes, Matos, \& Santos, 2011), a qualitative method that systematically analyzes how IMs emerge throughout the sessions. The method was first applied to a sample of women survivors of partner violence followed in narrative therapy (NT; Matos, Santos, Gonçalves, \& Martins, 2009), and it was later applied to other samples from different therapeutic models (e.g., 
emotion focused therapy [EFT] and client-centered therapy [CCT] for depression; Mendes et al., 2010; Gonçalves et al., 2012). In this study, we used the IMCS to analyze how IMs develop in a sample of complicated grief clients followed in grief therapy according to the meaning reconstruction approach (Neimeyer, 2001; 2006b).

\section{Innovative Moments Coding System}

The Innovative Moments Coding System (IMCS) identifies and differentiates five types of IMs: action, reflection, protest, reconceptualization and performing change. Additionally, it proposes the division of reflection and protest IMs into types 1 and 2 (Table I).

1. Action IMs are alternative behaviors and accomplishments that fall outside the behavioral repertoire constrained by the problematic self-narrative.

2. Reflection IMs refer to alternative thoughts, understandings and feelings different from what is imposed by the problematic self-narrative. They are divided into reflection 1 and 2:

2.1. Reflection 1(centered on the problem): the person creates distance from the problematic self-narrative by formulating new comprehensions about its causes and effects, aiming to overcome it.

2.2. Reflection 2 (centered on change): the person elaborates on the change process, for instance, considering the relevance of the therapeutic process and the strategies implemented to achieve self-transformation. Reflection 2 also involves the recognition of the difference between the past (problematic) and actual (alternative) self-narrative and feelings of well-being due to this insight.

3. Protest IMs involve new behaviors (such as Action IMs) and/or new thoughts (such as Reflection IMs) centered on criticizing the problematic selfnarrative and/or the persons who support it. This active criticism distinguishes protest from action and reflection (e.g., "I don't want this [facet of the problematic self-narrative] any more, I want to live my life in a different way, that's enough!'). It is divided into Protest 1 and 2:

3.1. Protest 1 (centered on the problem): involves a position of criticism towards the problematic selfnarrative or any source that feeds its power (e.g., a person or persons, particular self-positions)

3.2. Protest 2 (centered on new and empowered selfpositions): refers to a position of assertiveness in which the client affirms his or her rights and needs, assuming his or her well-being as an important priority. This new position fosters a sense of authorship and empowerment regarding the change process.

4. Reconceptualization IMs incorporate a personal recognition of two aspects of the change process: (1) the contrast between the old self (problematic self-narrative) and the emergent new self (alternative self-narrative) and (2) the awareness of the process that allowed this transformation. Thus, as a more complex and central type, reconceptualization involves not only the client's perception of the contrast between two positions (past and present) but also a meta-perspective position (Dimaggio, 2006) regarding the mechanisms that underlie this transformation.

5. Performing change IMs include the elaboration of anticipated or accomplished new experiences, investments, activities or skills that become possible as a consequence of the change process.

\section{Innovative Moments: The Heuristic Model of Psychotherapeutic Change}

In the past few years, several studies in psychotherapy have used the IMCS to explore the processes of narrative change in different samples and therapeutic approaches (Gonçalves et al., 2012; Gonçalves, Mendes, Ribeiro, Angus, \& Greenberg, 2010; Mendes et al., 2010; Ribeiro, Gonçalves, \& Ribeiro, 2009; Santos, Gonçalves, \& Matos, 2011; Santos, Gonçalves, Matos, \& Salvatore, 2009). Taking into consideration the main results of these studies, Gonçalves and collaborators (Gonçalves et al., 2009; Matos et al., 2009) have proposed a heuristic model of narrative change in brief psychotherapy, represented in Figure 1. According to this model, the pattern of successful change starts with the emergence of action, reflection and protest IMs, which may appear in different sequences throughout the initial and middle sessions. These are the most elementary IMs, representing clients' explorations of new ways of acting, feeling and thinking outside the problematic self-narrative domain. Although action, reflection and protest IMs constitute important forms of innovation, their continuous emergence and re-emergence, per se, seems to be insufficient for the development of an alternative self-narrative (Gonçalves et al., 2009). Reconceptualization, in turn, is recognized as the most complex form of innovation, associated with a meta-perspective or understanding of the particularities of the change process. Reconceptualization is also recognized as the IM that fosters the continuity of the change process by consolidating the meanings of previous IMs and promoting the integration of the following ones (Gonçalves et al., 2009; Gonçalves \& Ribeiro, 2012). In this sense, after the emergence of reconceptualization, new cycles of action, reflection and protest IMs emerge, validating the integration of the new self-narrative. Reconceptualization usually emerges in the middle phase of the treatment and progresses gradually until it ends in successful change. Performing change IMs tend to appear after 
Action

- New coping behaviors facing anticipated or existent obstacles

- Effective resolution of unsolved problem(s)

- Active exploration of solutions

- Restoring autonomy and self-control

- Searching for information about the problem(s)

Reflection

Type I. Creating distance from the problem(s)

- Comprehension - reconsidering causes of problem(s) and/or

awareness of its / their effects

- Formulation of new problem(s)

- Adaptive self-instructions and thoughts

- Intention to fight demands of problems, references of self-worth and/or

feelings of well-being

Type II. Centered on the change

- Therapeutic process - reflecting about the therapeutic process

- Change process - considering the process and strategies implemented to overcome the

problem(s); references of self-worth and/or feelings of well-being (as consequences of change)

- New positions - references to new/emergent identity versions in face of the problem(s)

Protest

Type I. Criticizing the problem(s)

Repositioning oneself towards the problem(s)

Type II. Emergence of new positions

Positions of assertiveness and empowerment

Reconceptualization

Reconceptualization always involves two dimensions:

- Description of the shift between two positions (past and present)

- The process underlying this transformation

Performing Change
Generalization into the future and other life dimensions of good outcomes

- Problematic experience as a resource in new situation

- Investment in new projects as a result of the process of change

- Investment in new relationships as a result of the process of change

- Performance of change: new skills

- Re-emergence of neglected or forgotten self-versions
C: Yesterday ... instead of staying in my bed crying all day, I took a ride to the city, visited the church to ask God to help me organize my life.

C: I want to live my life in a different way, trying to remember the things my daughter taught me. I'm sure she would say to me "keep going mom, you're on the right track.”

C: our sessions are helping me to accept this situation (the daughter's loss) in a more peaceful way, because now I know that I have strength to do this.

C: I'm tired of not having the right to cry and talk about my feelings and my sadness in front of others! It has to change!

C: I will not wear black clothes every day just to show others that I'm grieving! Not any more! Now I don't care, I wear what I want and no one has to do with it!

Let's think, for example, about the Mayan pyramids I climbed a few years ago. At the beginning I was stuck at the middle of the pyramid ... but then I realized that I couldn't be on that position forever, so I found a more stable spot... and started to get down slowly. Here (in therapy) it was the same, I didn't know how to deal with her loss and I learned gradually how to accept and (...) how to "go down" slowly into the ground (....) For example I started to give much more value to spiritual rather than physical things, and even if I lost a really beautiful daughter (physically), her actions and the way she helped persons were even much more beautiful (....) She's present in a different way.

C: Now I can feel her presence in my life in a different way, not in her house, in her clothes, or even at the cemetery. Now I feel her presence in my thoughts, in my new life, and I know that she is protecting me, and all my decisions to organize my life count with her strength. In the last week I started to plant new flowers on my back yard. I'm investing in "life" again, seeing these flowers growing every day because of me. She (the daughter) would be very proud of me! 


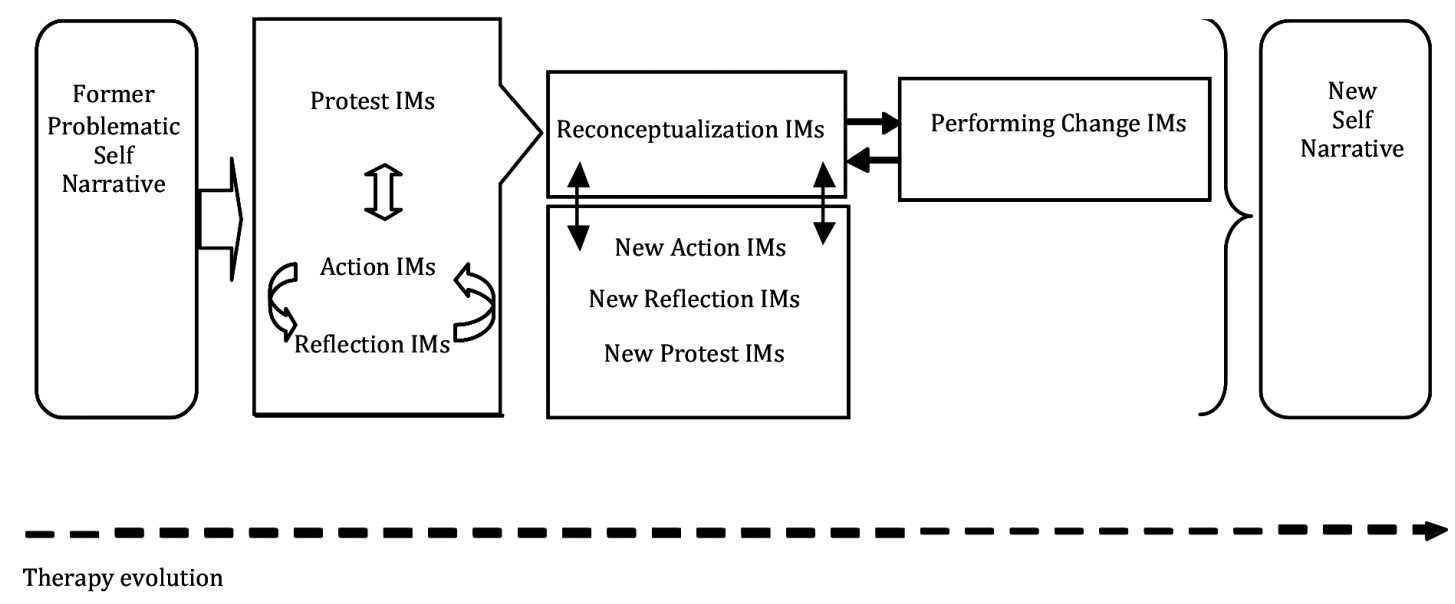

Figure 1. Heuristic model of change (Gonçalves et al., 2009).

reconceptualization and typically involve the performance of new skills developed due to the change process. Thus, the client is now able to invest in new projects or plans that are not just an attempt to combat or surpass the problem (being, in this way, different from action IMs). Performing change may also include the re-discovery of vanished parts of the self, as the person explores the new experiential repertoire. Finally, as reconceptualization and performing change progress, new action, reflection and protest IMs also occur, creating a pattern of congruent new meanings.

In unsuccessful therapy, in turn, the process of change-also initiated with action, reflection and protest IMs - seems to be blocked by the absence of reconceptualization IMs (Alves, Fernández-Navarro, Ribeiro, Ribeiro, \& Gonçalves, in press; Gonçalves et al., 2009; Matos et al., 2009; Mendes et al., 2010). These results highlight the role of reconceptualization as a key developmental process in clients' reintegration of painful experiences into a new selfnarrative (Cunha, Gonçalves, Valsiner, Mendes, \& Ribeiro, 2012).

\section{Innovative Moments in Grief Therapy: Previous Findings}

This study is anchored on the narrative-constructivist perspective that suggests that narrative activity is a central way of integrating the multiplicity of life experiences (even the more difficult life transitions) in a coherent, stable and flexible self-narrative through which persons give meaning to their lives (Neimeyer \& Levitt, 2001; White \& Epston, 1990). However, as suggested by Neimeyer (2001, 2006a), significant losses may menace this self-stability as the experience of losing a significant one may be an incoherent experience that contradicts the person's expectations about his or her life. When the self- narrative is not capable of assimilating this event, the person may develop a response of complicated grief (Neimeyer, 2006a). From a psychopathological perspective (Prigerson et al., 1995; Prigerson \& Maciejewski, 2006), complicated grief involves a prolonged grieving response characterized by high levels of separation distress, disturbing thoughts about the deceased (e.g., "I can hear his voice blaming me for his death"), significant difficulty accepting the loss and reorganizing life afterwards, and other symptoms that seriously impair the person's global functioning (e.g., persistent difficulty trusting others) (Prigerson et al., 2009).

A good deal of research (Coleman \& Neimeyer, 2010; Currier, Holland, Coleman, \& Neimeyer, 2007; Keesee, Currier, \& Neimeyer, 2008; Lichtenthal, Currier, Neimeyer, \& Keesee, 2010; Neimeyer, Baldwin, \& Gillies, 2006) suggests that the capacity to integrate loss into the personal self-narrative is a strong predictor of grief severity, highlighting the centrality of these meaning-making processes in grief adaptation. In the past few years, there have been a growing number of empirical studies supporting the effectiveness of meaning-oriented interventions in complicated grief (Lichtenthal \& Cruess, 2010; MacKinnon et al., 2011, 2012). The meaning reconstruction approach proposed by Neimeyer (2001, 2006b) offers a reflective context for helping clients acknowledge and renegotiate the meanings of their experiences, in a more experiential, co-constructed and creative - rather than "cognitive," corrective and well-structured-way (Neimeyer, 2009; Neimeyer, Burke, Mackay, \& van Dyke-Stringer, 2010). It proposes the reconstruction of clients' problematic self-narratives (inflexible stories of loss) and the investment in a more flexible self-narrative, capable of incorporating more positive and flexible meanings of their losses (Neimeyer et al., 2010). 
Considering the relevance of these constructivistnarrative approaches in transforming clients' stories of loss, recent studies using the IMCS in grief therapy using the meaning reconstruction approach have been developed that explore how narrative novelties (IMs) emerge throughout therapy and how they promote change. In a good-outcome case of grief therapy with a bereaved mother, Alves, Mendes, Gonçalves and Neimeyer (2012) found that the emergence and development of IMs were associated with the client's progressive clinical change, as the client gradually transformed the problematic self-narrative into a more healthful story of loss. Mostly elaborating on reflection IMs throughout therapy, this client gradually progressed to reconceptualization at the middle phase of treatment, finishing by elaborating on new life investments through performing change IMs. In general, the results of this study corroborated the heuristic model of change presented earlier, with the exception of the almost absence of protest IMs throughout the entire treatment. According to the authors, this absence could be associated with the constructivist view of complicated grief, pointing to the acceptance and integration of loss as the main therapeutic goal, rather than the elaboration of a position of criticism towards the story of loss.

Another recent study using the IMCS in grief therapy was developed (Alves et al., in press) to analyze the change processes in two grief cases, a "recovered" case of a woman who lost her grandmother and an "improved but not recovered" case of a woman who lost both her son and her husband. The results of this study were also in line with the main hypothesis of the heuristic model of change (Gonçalves et al., 2009), with the "recovered" case progressing from reflection to reconceptualization in the more advanced stages of therapy, contrasting with the relative absence of reconceptualization in the "improved but not recovered" case. Action, protest and performing change IMs were also nonexistent in both cases. In that study, Alves et al. (in press) also explored how IMs were organized around central themes (Ribeiro, Bento, Salgado, Stiles, \& Gonçalves, 2011, termed these themes protonarratives) that emerged throughout treatment, which were alternative to the themes of the problematic self-narrative. The results suggested the emergence of two central themes involved in the process of self-transformation in both the "recovered" as well as in the "improved but not recovered" case: "Integration" and "Proactivity." "Integration" was the most salient theme in both cases, incorporating all IMs that addressed the client's construction of a healthier symbolic connection with the deceased, integrating loss in a more representational way (e.g.,
"Now I feel that she's with me in another way... I can even look at her picture on the grave and feel peace"). The centrality of this theme is congruent with the findings from Keesee et al. (2008) and Lichtenthal et al. (2010), pointing to the capability to "make sense of" and integrate loss as a central aspect in bereavement adaptation. It is also in line with the "loss orientation" process proposed by Stroebe and Schut (1999) in their "Dual Process Model," addressing the relevance of the griever's concentration on exploring the multiple meanings and challenges of loss itself, including how to reestablish a different connection with the lost person. Finally, "Proactivity" incorporates all IMs addressing the client's search for moments of well-being and life reconstruction as alternatives to the extreme painful grief (e.g., "I'm trying to do other things, not being always at home... Sometimes I go for a walk with some friends"). This theme also seems to be consistent with the "Dual Process Model" (Stroebe \& Schut, 1999), more specifically with the "restoration orientation" phase, which is focused on grievers' investments in life restoration (new roles, relationships, activities) as a way to cope and adapt to the multiple life changes after loss. According to this model, the oscillation between "loss orientation" and "restoration orientation" is necessary for adaptive grieving. Due to the relevance of these processes and how they can inform the client's movement toward positive grief adaptation, "Integration" and "Proactivity" will also be addressed in the present study.

\section{The Present Study}

The overall purpose of this study is to investigate how IMs - as opportunities for self-transformationoccur throughout therapy and how their emergence and expansion are associated with the integration of loss ("Integration") and the search for well-being and life reorganization ("Proactivity"), identified as relevant processes in loss adaptation (Alves et al., in press).

In general, we anticipate that the global pattern of IMs in this sample will be consistent with the heuristic model of change (Gonçalves et al., 2009), thus being congruent with the findings from previous studies in NT, EFT, CCT and grief therapy using the meaning reconstruction approach. Because one of the central goals of this approach to grief therapy (Neimeyer, 2001, 2006b) is the promotion of new understandings of loss, we hypothesize a high prevalence of reflection IMs in all cases, expressing clients' investment in the meaning reconstruction of this experience. We also anticipate a higher probability of reconceptualization IMs occurring in cases with greater symptomatic improvement (pre-post 
clinical scores). Finally, considering the promotion of a healthier connection with the deceased and the stimulation of new forms of life reorganization as central aspects of grief therapy (Neimeyer, 2001, 2006b), we anticipate a gradual evolution of "Integration" and "Proactivity" across therapy, with a higher probability of occurrence of these two themes in cases with greater symptomatic improvement.

Considering the hypothesis addressed above, the main research questions of this study are as follows:

(1) Is the IMCS a reliable method to identify IMs in grief therapy using the meaning reconstruction approach?

(2) Are there significant differences in the probabilities of overall IMs occurring over time (throughout the sessions) among cases with different symptomatic improvements?

(3) Are there significant differences in the probabilities of specific IM types occurring over time among cases with different symptomatic improvement?

(4) Are there significant differences in the probabilities of each theme occurring over time in cases with different symptomatic improvement?

\section{Method}

\section{Clients}

Clients were recruited from our "Complicated Grief Research Study," designed to explore the processes of narrative change in grief therapy according to the meaning reconstruction approach (Neimeyer, 2001, $2006 b$ ). In order to enroll clients who evidenced a problematic response to a significant loss, arrangements were made with the main hospital and with two health centers of our city to refer suitable clients for psychological assessment at the clinical psychology center of our university. More specifically, the physicians from those institutions were informed by their ethical departments about this project and were asked to refer all the patients whom they identified as having a persistent and difficult reaction to a significant loss for a minimum period of 6 months.

A total of 10 clients were referred for evaluation of eligibility. All of them attended an initial evaluation session for this purpose.

Two participants dropped out, one at the fourth session, without giving a reason, the other at session 11 at the end of the treatment protocol, when there were no further clinical symptoms and there were conflicts with her commitment to attending to a sick husband.
Besides the two dropouts, two other cases were not included in this sample. These two other persons lost their loved ones a few days before their physicians referred them, not being considered as "complicated grief" cases (notice that we follow the guidelines proposed by Prigerson and collaborators, suggesting the period of 6 months as a criterion for complicated grief). However, they were also offered psychological support regarding their loss but not the same intervention protocol initiated with the complicated grief clients. Both persons said that they were not interested in sharing their experiences of loss at that moment. Thus, at the end we had 6 clients participating in the study.

Each recruited client was followed weekly in individual grief therapy according to the meaning reconstruction approach (Neimeyer, 2001, 2006b). The clinical protocol established 15 sessions of therapy. All sessions were video recorded and transcribed. In accordance with the ethics protocol approved by the hospital, clients gave written informed consent for their materials to be used for the research.

The 6 cases integrated in this sample were Caucasian women (age range $=20-62$ years, $M=$ 42 years, $S D=18.63$ ) and completed an average of $13.83(S D=0.98)$ sessions. This included the two cases from the study referred to previously, from Alves et al. (in press).

Among the clients included in this sample, 5 had lost one significant person, and one client had lost two significant persons. At the pre-therapy assessment meeting, the 6 cases presented with the following circumstances, causes and time since loss: loss of a grandmother to a stroke, 3 years before therapy (case 1); loss of a boyfriend to cancer, 2 years before therapy (case 2); loss of a husband to cancer, 2 years before therapy (case 3); loss of a daughter to cancer, 2 years before therapy (case 4 ); loss of a son (to cancer, 3 years before therapy) and husband (who was run over by a car, 6 months before therapy) (case 5); and loss of a mother to stroke, 1 year before therapy (case 6). Two clients maintained stressful relationships with other family members (e.g., economic and marital problems) that also had an impact on their mental well-being, although these difficult relationships were not as central as the complicated grief. Thus, work on these relationships areas was also included throughout their treatment.

\section{Therapist}

All clients were treated by the same female therapist, a 26-year-old clinical psychology doctoral student with 3 years of prior clinical experience as a 
psychotherapist and 2 years of experience in grief therapy according to the meaning reconstruction approach (Neimeyer, 2001, 2006b). A trained therapist with 18 years of clinical experience as a constructivist psychotherapist supervised the clinical practice to ensure adherence to the constructivist principles. The supervision took place three to four times per month, and it was based on a structured verbal report of each session. This periodicity was adjusted in order to accommodate all the video recorded sessions of the previous week. On average, each supervision meeting lasted 2 to 3 hours. Supervision meetings were also oriented to conjointly organize the therapeutic activities of the next sessions with each client, privileging, in this way, the adherence to the constructivist meaning reconstruction approach. However, no specific adherence scale was used.

\section{Therapy}

The therapy was conducted according to the constructivist meaning reconstruction approach proposed by Neimeyer (2001, 2006b). Although the treatment was not oriented through a structured manual, it always included an initial exploration of the client's experience of loss, oriented by the "Meaning Reconstruction Interview" (Neimeyer, 2006b, pp. 166-169). This first contact aimed to explore and validate the multiple challenges and resources of each client. Then, the therapeutic process developed through the articulation of several narrativeconstructivist activities (e.g., "narrative retelling"; Neimeyer et al., 2010, p. 76; "imaginal conversations with the deceased"; Shear, Boelen, \& Neimeyer, 2011 , p. 149), implemented in order to foster a less anguished elaboration of grief (Neimeyer et al., 2010) and the construction of a more positive connection with the deceased (Field, 2006; Shear et al., 2011).

\section{Researchers}

The first author (judge 1) analyzed the IMs in all six cases. The second and third authors were also judges in the IM coding process. More specifically, the second author (judge 2) coded all IMs from three cases and the third author (judge 3) coded all IMs from two cases. All three judges were doctoral students in clinical psychology with practice in IM coding procedures. Finally, the fourth and fifth authors, who supervised and contributed to the elaboration of this study, were university members in clinical psychology and experienced researchers and psychotherapists. Judge 1 and author 4 had 2 and 18 years of practice, respectively, in constructivist therapy. Except author 4, all the other research- ers were trained in the IM coding process. More specifically, judge 1 had 2 years of training on this approach, judge 2 had 6 months, judge 3 had 3 years of experience in IM coding and author 5 had 8 years of experience in IM coding.

\section{Measures}

\section{Outcome measures}

Structured Clinical Interviews for DSM-IV-TR, Axis I (SCID-I; First, Spitzer, Gibbons, \& Williams, 2002) and Axis II (SCID-II; First, Gibbon, Spitzer, Williams, \& Benjamin, 1997). Grounded in DSMIV-TR diagnostic criteria, SCID-I and SCID-II are structured clinical interviews that assess clients' disorders on axis I (mood, psychotic and anxiety disorders) and axis II (personality disorders). SCID-I also enables the collection of relevant demographic and clinical data about the participants. Inter-rater reliability ranged from .83 to .85 on the SCID-I (DelBen et al., 2001) and was .63 on the SCID-II (Weertman, Arntz, Dreessen, Velzen, \& Vertommen, 2003).

Inventory of Complicated Grief (ICG; Prigerson et al., 1995). The ICG is a 19-item questionnaire to assess the severity of grief symptomatology. The items (e.g., "I feel that life is empty without the person who died") are rated on a 5-point Likert scale, from 0 ("never") to 4 ("always"), with total scores ranging from 0 to 76 . A score above 25 at least 6 months after loss suggests complicated grief. The instrument shows good internal consistency (.94; Prigerson et al., 1995). We used the Portuguese adaptation by Frade, Rocha, Sousa and Pacheco (2009), which also presents good internal consistency (.91; Frade et al., 2009). The cut-off score for the Portuguese population is 30 (Sousa \& Rocha, 2011). The internal consistency of the ICG in the present study was .84 .

Beck Depression Inventory-II (BDI-II; Beck, Steer, \& Brown, 1996). The BDI-II is a 21 -item questionnaire that assesses the severity of depressive symptomatology over the previous 2 weeks. The items (e.g., self-dislike, pessimism) are rated on a 4-point Likert scale, from 0 to 3 , with total scores ranging from 0 to 63 . The instrument shows high internal consistency (.91; Steer, Brown, Beck, \& Sanderson, 2001). We used the Portuguese adaptation by Coelho, Martins and Barros (2002), with a cut-off of 14.29 and a Reliable Change Index (RCI; Jacobson \& Truax, 1991) of 8.46, as proposed by Seggar, Lambert, and Hansen (2002). The internal consistency of the BDI-II in the present study was .71. 


\section{Process Measures}

Innovative Moments Coding System (IMCS; Gonçalves, Ribeiro, et al., 2010; Gonçalves, Ribeiro, Mendes, et al., 2011). The IMCS (Table I) is a qualitative method of analysis that identifies five categories of Innovative Moments (IMs): action, reflection, protest, reconceptualization and performing change. Previous studies with the IMCS (Gonçalves et al., 2012; Matos et al., 2009; Mendes et al., 2010) reported reliable agreement between judges in IM coding, with Cohen's kappa between .86 and 97. (Reliability for this study is reported at the Results section.)

\section{Procedures}

\section{Outcome measures}

In the first meeting with the therapist (assessment meeting), all clients were evaluated with the SCID-I (First et al., 2002) and SCID-II (First et al., 1997) clinical interviews to assess co-morbidity with other psychological problems that could be clinically more central than the complicated grief. To screen specifically for complicated grief symptoms, the Portuguese version of the ICG (Frade et al., 2009) was administered. Considering the relationship between grief distress and depressive symptomatology (Bonanno \& Mancini, 2006), clients' depressive symptoms were also assessed using the BDI-II (Coelho et al., 2002). Both the ICG and the BDIII were then administered every fourth session as well as in the final session and at the 6-month follow-up meeting.

All six clients were diagnosed with complicated grief in the assessment meeting. Five of them were also diagnosed with major depression, as defined by the DSM-IV (American Psychiatric Association, 1994).

Despite research evidence suggesting comorbidity between complicated grief and Post-Traumatic Stress Disorder (PTSD; McDevitt-Murphy, Neimeyer, Burke, Williams, \& Lawson, 2012), none of the cases met the criteria for a PTSD diagnosis.

\section{Process Measures}

Innovative Moments Coding System (IMCS): IMs identification, coding and reliability. In this study, the IMCS was applied to a total of 83 sessions, corresponding to all sessions of the six clients. Judge 1 coded $100 \%$ of the sample ( 83 sessions), judge 2 coded independently $50.6 \%$ of the sample (three cases, 42 sessions) and judge 3 coded
$33.7 \%$ of the sample (two cases, 28 sessions). Judges 2 and 3 were unaware of the cases' clinical outcomes in all the instruments applied.

The IM coding procedure involved (1) a consensual definition of the client's problematic self-narrative between judges, (2) identification of IMs within the transcripts, recording the number of words involved in each one, and (3) categorization of each IM by type.

(1) Consensual definition of client's problematic self-narrative. The problematic self-narrative was evaluated from the perspective of what therapist and client discussed during therapy, having in mind what were their main therapeutic targets. This evaluation was done in a consensual way, using the contributions of all judges. That is, each judge organized an independent list of problems that was discussed in order to generate a consensual list of problems from which the facets of the problematic self-narrative were defined. The final definition of this list of problematic facets oriented, then, the recognition of IMs (as exceptions to it).

(2) Identification of IMs along the text. After the consensual establishment of each client's problematic self-narrative facets, all sessions were coded independently according to their sequential order. The identification of IMs occurred every time the therapist or client started to elaborate upon exceptions to the problematic self-narrative. It was considered that an IM ended when the person stopped elaborating this content. Each IM onset and offset was then identified and the amount of words involved in each one was recorded (this amount of words is termed salience). The therapist's words were also recorded, given our perspective on the coconstructed nature of the change process (Angus, Levitt, \& Hardtke, 1999; Neimeyer, 2009). In this sense, the IM elaboration could result from questions or activities proposed by the therapist, but they were only coded if the client accepted and further elaborated upon it.

(3) Categorization of each IM in terms of type and salience. After the IMs were identified, their types were categorized. To compute each IM's salience - that is, the amount of text involved in the elaboration of IMs - the authors calculated the following items:

(a) The salience of each type of IM for each session, corresponding to the percentage of words in the session devoted to each IM. Salience was computed by calculating the 
number of words involved in each type, divided by the total number of words in the transcript of the session.

(b) Overall salience of the IM, calculated as the sum of all words incorporated into IMs in a given session (independent of the type), divided by the total number of words of the session.

(c) The mean salience for the entire case, by IM type and overall, calculated as a mean of the percentage of each type and the overall IMs.

The percentage of agreement between judges regarding overall salience of the IMs was calculated as the amount of overlapping words identified by both judges as being from IMs, divided by the total amount of words identified by each judge. The agreement between judges for the specific type of IM was assessed with Cohen's kappa. To further explore the details of the IMCS' administration, please see Gonçalves et al., (2012), Gonçalves, Ribeiro, Mendes et al., (2011), Matos et al., (2009) and Ribeiro et al. (2011).

\section{Thematic Analysis: Theme Identification and Coding}

The thematic analysis (Braun \& Clarke, 2006) was used in order to integrate each IM coded into the categories pre-established as relevant to loss adaptation in a previous study (Alves et al., in press). The types of IMs were established prior to this analysis. This process involved repeated readings of the transcripts followed by an intensive analysis of each IM's content. Thus, each IM from all six cases (83 sessions) was then integrated into one of the themes pre-established as relevant to loss adaptation: "Integration" and "Proactivity." Those IMs whose content was not associated with either "Integration" or "Proactivity" were referred to the category "Others." Further explanation regarding the description of each theme will be provided in the results section. Judges 1 and 2 coded the themes of the same three cases they had previously coded for IMs, reaching a consensus regarding the final coding decision. Judge 1 individually coded the themes of the other three cases.

\section{Results}

\section{Is the IMCS a Reliable Method to Identify IMs in Grief Therapy Using the Meaning Reconstruction Approach?}

A total of 3293 IMs were identified in this sample using the IMCS. The percentage agreement in the overall salience of IMs in the cases coded by judges 1 and 2 was $89.2 \%$, and between judges 1 and 3 it was $83.7 \%$. Both results indicate a high degree of consensus regarding the number of words coded as belonging to IMs throughout the cases, independently of the specific type.

Reliability for the specific types of IMs (e.g., action, reflection) assessed by Cohen's kappa was .91 between judges 1 and 2 and .80 between judges 1 and 3. Reliability on reflection and protest types (1 and 2) was .83 between judges 1 and 2 and .79 between judges 1 and 3 . These results indicate a strong agreement among coders regarding IMs types (Hill \& Lambert, 2004).

The mean overall salience of the IMs in this sample was $22.9 \%$. Reflection IMs represented $17.5 \%$ of the text coded as IMs, divided almost equally among type 1 at $9.2 \%$ and type 2 at $8.3 \%$. Reconceptualization was the second most salient IM (3\%). The total salience of the other IMs was lower than $2.5 \%$.

\section{Are There Significant Differences in the Probabilities of Overall IMs Occurring Over Time (Throughout Sessions) Among Cases with Different Symptomatic Improvement?}

Similar to the study design proposed by Gonçalves et al. (2012), the data were explored using a generalized linear model (GLM), considering the salience of each type of IM as the response variable, and "time" along treatment, the "symptomatic improvement" and the "interaction between time and symptomatic improvement" as explanatory variables. The analyses described in this study (GLM analysis) are similar to a regression analysis, with the difference that measures along treatment were used, allowing this way to identify change patterns over time. Regarding the variable symptom improvement, four cases (cases 1, 2, 3 and 4) showed a clinical change in complicated grief, with final scores lower than 30 (considering the cut-off score of 30 established for the Portuguese version of the ICG; Sousa \& Rocha, 2011). In contrast two cases (cases 5 and 6) didn't achieve a clinical change in complicated grief symptomatology at the end of treatment. Considering the BDI-II cut-off score of 14.29 (Coelho et al., 2002) and the Reliable Change Index (RCI; Jacobson \& Truax, 1991) of 8.46 proposed by Seggar et al. (2002), three cases (cases 1, 4 and 6) showed a significant clinical change in depressive symptomatology while two cases (cases 3 and 5) didn't achieve a significant clinical change in depressive symptomatology at the end of treatment. Table II shows the pre and post ICG and BDI-II scores for each case.

Taking into consideration the central goal of studying the development of IMs in grief change, 
we decided to consider grief symptomatology (assessed with the ICG) as the sole explanatory variable for clients' symptomatic improvement. Thus, we did not include the depressive symptomatic improvement as another explanatory variable, although we considered it to be relevant information for sample pre- and post-characterization.

Based on our GLM analysis, the probability of "non-occurrence of an IM" or the "occurrence of a certain type of IM" was illustrated as a binary response variable $0 / 1$. It was treated as a random variable with Bernoulli distribution, and the main goal was to infer the probability parameter associated with this distribution. A generalized linear mixed effects model was adopted, incorporating a subjectspecific random effect to take into account variability among individuals. A correlation between measurements from the same subject was expected.

According to the literature, we estimated that

$\mathrm{P}$ (occurrence of an IM of a certain typeexplanatory variables) $=\mu$

where the explanatory variables have a linear effect on the probability through a link function so that

$$
\mu=(\exp (\eta)) /(1+\exp (\eta))
$$

The interpretation of $\eta$ is the logarithm of the odds ratio between occurrence and non-occurrence of an IM; more specifically,

$$
\eta=\log (\mu /(1-\mu))
$$

The explanatory variables were then considered

$$
\eta=\beta \times x
$$

in which the vector $\mathrm{X}$ is of all the significant explanatory variables, and $\beta$ corresponds to the vector of the parameters to be estimated.

The process of fitting the data to this model showed that the selected model resulted, which included only the significant explanatory variables; more specifically,

$$
\begin{aligned}
\eta= & \beta 0+\beta 1 \times \text { Session }+\beta 2 \times(\text { ICG_pre } \\
& - \text { ICG_post })+\beta 3 \times \text { Session } \times(\text { ICG_pre } \text {. } \\
& - \text { ICG_post }),
\end{aligned}
$$

in which $\beta 1 \times$ session is the effect of time (the evolution of treatment from session 1 to the last session), $\beta 2 \times$ (ICG_pre-ICG_post) is the improvement in complicated grief symptoms (that is, the difference between the initial and final ICG scores), and finally, $\beta 3 \times$ Session $\times\left(I C G \_p r e-I C G \_p o s t\right)$ is the interaction of time with the improvement in symptoms.

The results for overall IM probability are illustrated in Figure 2. Axis y depicts the probability of overall IM occurrence, and axis $\mathrm{x}$ depicts the evolution of therapeutic sessions over time. The different grey gradients of the lines represent the level of pre- to post-assessment improvement in ICG scores. The lighter lines represent cases with the greatest symptomatic improvement (the lighter line at the top of Figure 2, for example, depicts the results from case 4 , the one with the highest difference (37) in the pre- and post-test ICG scores). The darker lines, on the other hand, represent cases with lower improvement (the line at the bottom of Figure 2, for example, depicts the results from case 5 , the one with the lowest difference (13) in pre- and post-test ICG scores). The other lines with different degrees of grey in between these extremes represent the other four cases (the specific pre- and post-test score differences in the ICG are represented in Table II for all cases). This representation through distinct gradients of grey will be consistent throughout all figures presented below. Notice that, as the results of the three cases with lower symptomatic improvement (depicted by the darker grey lines) were very similar, the three lines corresponding to these three cases overlapped, appearing as just one darker line in all the figures.

The GLM analysis for overall IMs showed that the parameter "symptomatic improvement" had no significant effect on the probability of overall IMs $(p=.897)$. In contrast, the parameters "time" $(p<.0001)$ and "interaction between time and symptomatic improvement" $(p<.0001)$ both had significant positive effects in the overall probability

\begin{tabular}{|c|c|c|c|c|c|c|}
\hline Case & Pre-test ICG & Post-test ICG & Improvement in the ICG & Pre-test BDI-II & Post-test BDI-II & Improvement in the BDI-II \\
\hline Case 1 & 42 & 11 & 31 & 26 & 8 & 18 \\
\hline Case 2 & 39 & 25 & 14 & 14 & 13 & 1 \\
\hline Case 3 & 61 & 28 & 33 & 24 & 18 & 6 \\
\hline Case 4 & 58 & 21 & 37 & 23 & 12 & 11 \\
\hline Case 5 & 55 & 42 & 13 & 35 & 15 & 20 \\
\hline Case 6 & 51 & 36 & 15 & 33 & 13 & 20 \\
\hline
\end{tabular}
of occurrence of IMs, meaning that cases with different symptomatic improvements started to significantly differ from each other as the treatment progressed. As shown in Figure 2, despite the

Table II. ICG (cut-off score 30) and BDI-II (cut-off score 14.29) pre and post scores 
similarity in IMs probability from baseline until session 6, from this moment onwards, cases with greater symptomatic improvement (illustrated by the lighter grey lines) changed the probability of having IMs with a higher rate over time than cases with less improvement (illustrated by the darker lines).

\section{Are There Significant Differences in the Probabilities of Specific IMs Occurring Over Time in Cases with Different Symptomatic Improvement?}

The data for each type of IM were modeled independently. This model enabled the analysis of the various parameters indicated above regarding the overall probability of occurrence of IMs, as well as the probability of each specific IM type. Parameter 1 $(\beta 1 \times$ session) allowed for a study of the impact of time in the probability of IM emergence, exploring whether the probability of IMs increased or decreased during the treatment. Parameter $2(\beta 2 \times$ (ICG_pre - ICG_post)) allowed for a study of the impact of grief symptomatic improvement on the probability of IM occurrence. Finally, parameter 3 $(\beta 3 \times$ Session $\times($ ICG_pre - ICG_post) $)$ enabled an analysis of the interaction between time and grief symptomatic improvement, taking into consideration the rate of change in the symptomatology.

In general, the results showed that the IMs with the lowest probability of occurrence were action, protest 1 and protest 2 , all with probabilities lower than $1 \%$. Performing change IMs had a maximum probability of occurrence of approximately $3.5 \%$ in the last session of case 4 (the case with the highest

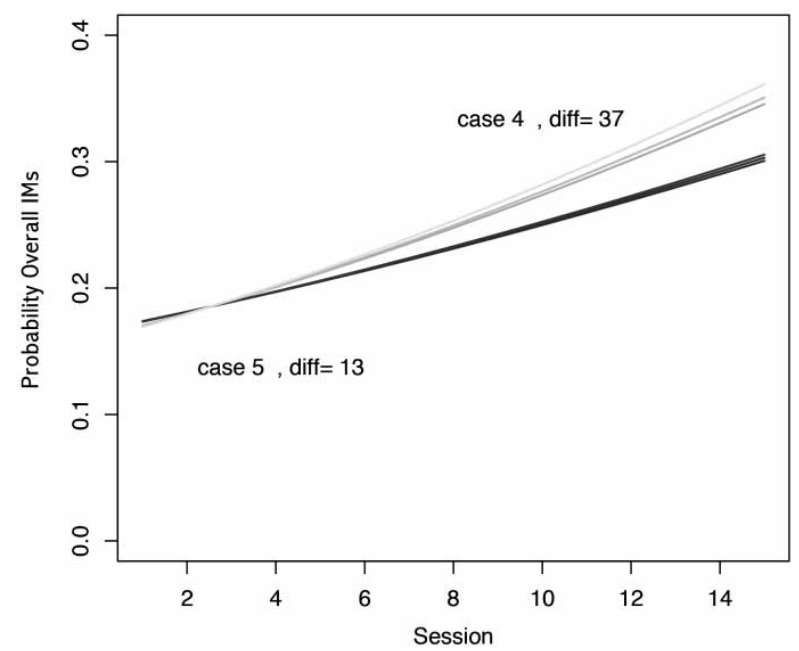

Figure 2. Probabilities of overall IMs. The different gradient lines represent the evolution of overall IM probabilities among cases with different pre to post differences in the ICG. Only the cases with extreme pre-post differences (4 and 5) are labeled in the figure. symptomatic improvement). Reflection 1, reflection 2 and reconceptualization, in contrast, were the IMs with the highest probability of occurrence, with maximum probabilities of approximately $13 \%, 15 \%$ and $25 \%$, respectively. Given these differences in the probabilities of different types of IMs, we concentrated our analysis of the results just on those IMs that were most prevalent, that is, reflection 1, reflection 2, reconceptualization and performing change.

The GLM analysis showed that, similarly to what occurred with the overall IMs, the parameter "symptomatic improvement" had no significant effect on the probability of reflection $1(p=.622)$, reflection $2 \quad(p=.33)$ or reconceptualization $(p=.681)$. Performing change was the only IM in which the parameter "symptomatic improvement" showed a significant positive impact $(p<.0001)$.

The parameters "time" and "interaction between time and symptomatic improvement," in contrast, had significant effects on the probability of reflection 1 , reflection 2 and reconceptualization, which will be explored below.

The results of reflection 1 (mainly centered in clients' intentions to live grief in a different way) are illustrated in Figure 3. Both "time" $(p<.0001)$ and the "interaction between time and symptomatic improvement" $(p<.0001)$ negatively affected its probability of occurrence. That is, the probability of reflection 1 decreased progressively from the beginning to the end of the treatment, with cases with greater symptom change (ICG) having a faster reduction in this IM than cases with lower symptomatic improvement.

Unlike reflection 1, the parameters "time" $(p<.0001)$ and "interaction between time and symptomatic improvement" $(p<.0001)$ positively affected the probability of occurrence of reflection 2 (mainly centered on clients' elaboration about the strategies implemented to live grief in a more adaptive way). As illustrated in Figure 4, the probability of this IM gradually increased over time in all cases, with a higher rate of change in cases with greater symptomatic improvement (depicted by the lighter grey lines). For example, in case 4 (the case with greatest symptomatic improvement), the probability of reflection 2 progressed from approximately $6 \%$ at baseline to $15 \%$ in the last session, which was the maximum probability reached by this IM in the entire sample.

Similarly to reflection 2, reconceptualization was also positively affected by the parameters "time" $(p<.0001)$ and "interaction between time and symptomatic improvement" $(p<.0001)$. As shown in Figure 5, from session 6 onwards the rate of increase of this IM was higher in cases with greater 


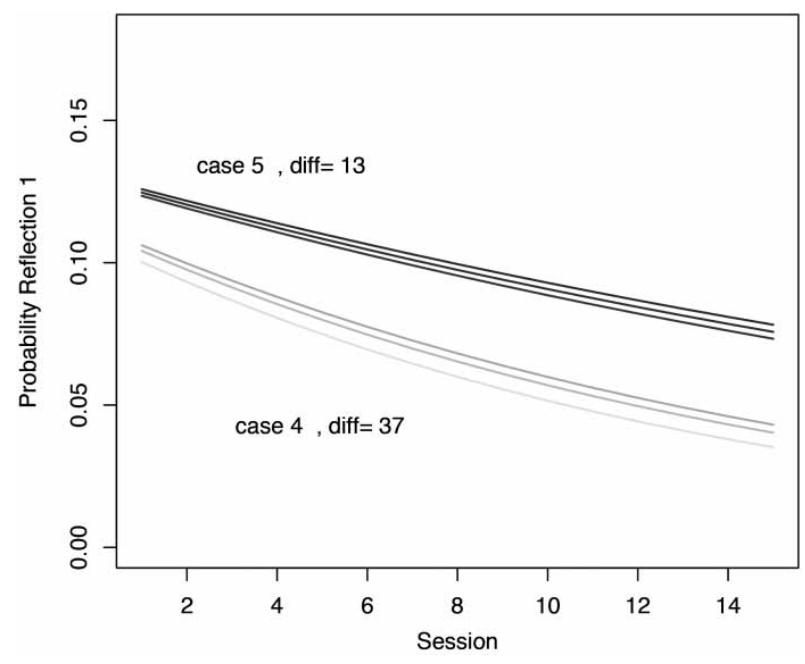

Figure 3. Probabilities of reflection 1 IMs. The different gradient lines represent the evolution of reflection 1 IM probabilities among cases with different pre to post differences in the ICG. Only the cases with extreme pre-post differences (4 and 5) are labeled in the figure.

symptomatic improvement (depicted by the lighter grey lines), with case 4 reaching the maximum probability of this IM (25\%) in the last session.

Finally, performing change IMs were positively affected by all parameters studied $(p<.0001)$. As seen in Figure 6, until session 11, the probabilities were quite similar for all cases, but from session 11 onwards the cases with greater symptomatic improvement showed a higher rate of increase in this IM. Similar to what occurred with previous IMs, the maximum probability of this IM (3.5\%) was reached in the last session of the case that evidenced the greatest symptomatic improvement (case 4).

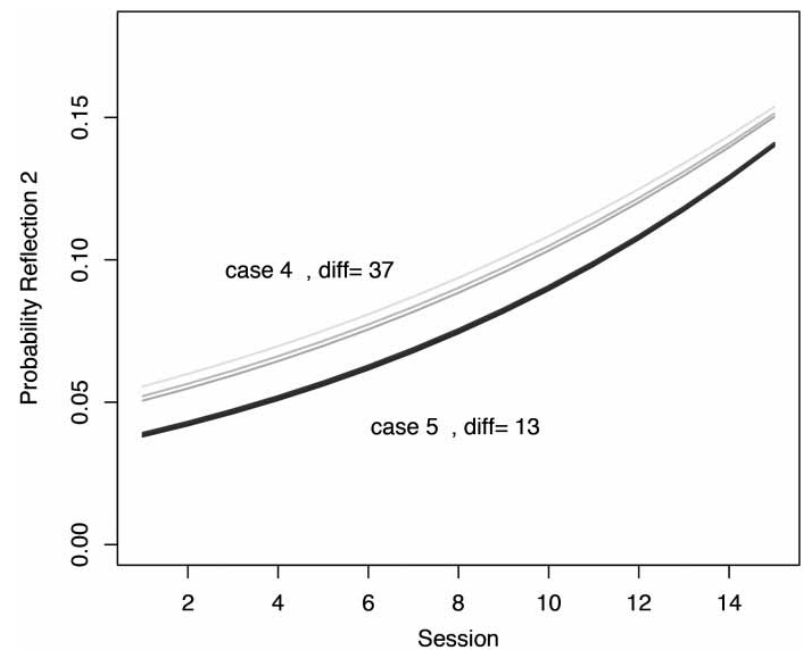

Figure 4. Probabilities of reflection 2 IMs. The different gradient lines represent the evolution of reflection 2 IM probabilities among cases with different pre to post differences in the ICG. Only the cases with extreme pre-post differences (4 and 5) are labeled in the figure.

\section{Are There Significant Differences in the Probabilities of Each Theme Occurring Over Time in Cases with Different Symptomatic Improvement?}

An exploratory analysis of the data showed that the most salient theme in the entire sample was "Proactivity" (38.8\%), followed by "Integration" (33.1\%) and "Others" (28.1\%).

As described above, "Proactivity" integrated all IMs associated with the clients' search for moments of well-being (e.g., going for a walk in the nearby city) that are alternatives to the extreme pain lived since loss. The theme "Integration" consisted of all IMs associated with the client's investment in new forms of connection with the lost person(s), creating a more positive and adaptive meaning for his or her loss. Finally, "Others" integrated other forms of narrative elaboration related to the experience of grief, such as "Self-forgiveness" (3.9\%, referring to the client's self-forgiveness regarding past decisions involving the lost ones), "Acceptance of death" (3.3\%, referring to the client's assimilation of the notion of death as a universal experience that could be liberating to ill persons) and "New Investments" (8.8\%, referring to the client's involvement in new projects, such as having a new job, as a consequence of change). This last category also included the theme "Assertiveness" (12.1\%), which was not directly related to the grief experience but to the adoption of assertive positions towards abusive relationships or active resolution of other interpersonal conflicts in general.

The probabilities of "Integration" and "Proactivity" considering the results for the overall IMs are

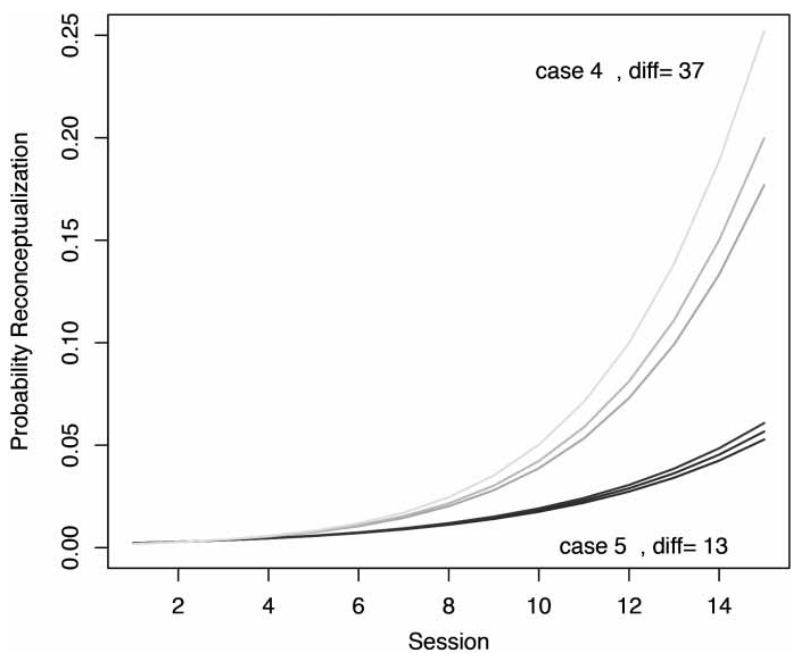

Figure 5. Probabilities of reconceptualization IMs. The different gradient lines represent the evolution of reconceptualization IM probabilities among cases with different pre to post differences in the ICG. Only the cases with extreme pre-post differences (4 and 5) are labeled in the figure. 


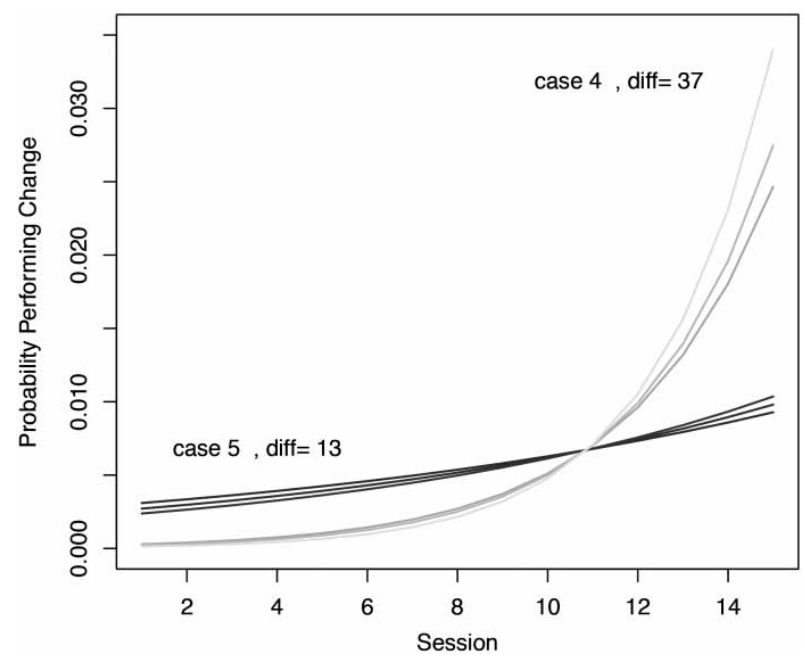

Figure 6. Probabilities of performing change IMs. The different gradient lines represent the evolution of performing change IM probabilities among cases with different pre to post differences in the ICG. Only the cases with extreme pre-post differences (4 and 5) are labeled in the figure.

illustrated in Figure 7. The highest probability of "Integration" occurring was approximately 14\% (last session of case 4 , the case with the greatest grief symptomatic improvement). The highest probability of "Proactivity" occurring was approximately $12 \%$ (also during the last session of case 4 ). The GLM analysis showed that neither "Integration" $(p=.45)$ nor "Proactivity" $(p=.81)$ showed significant differences associated with the parameter "symptomatic improvement." However, both themes' probabilities were positively affected by the evolution of time $(p<.0001)$ and by the interaction between time and symptomatic improvement $(p<.0001)$. As depicted in Figure 7, the differences between cases regarding the elaboration of both themes started to become more visible as treatment progressed, especially from session 6 onwards. In general, "Integration" was the theme in which the rate of evolution over time was most evident, especially in the cases with greater symptomatic improvement (as depicted by the lighter grey lines in Figure 7).

Finally, we will briefly describe the results regarding the interaction between each theme and the emergence of specific types of IMs. In general, the results show a progressive movement from the elaboration of IMs more centered on fighting the problem (reflection 1) to the elaboration of IMs more centered on the change process (reflection 2) in both themes. While the probability of reflection 1 decreased significantly over time both in "Integration" $(p<.0001)$ and "Proactivity" $(p<.0001)$, the probability of reflection 2 , in turn, increased significantly over time, both in "Integration" $(p<.0001)$ and "Proac- tivity" ( $p<.0001)$. The probability of reconceptualization over "Integration" and "Proactivity" was also significant $(p<.0001)$. However, the progression over time of this IM was only significant in "Integration" $(p<.0001)$.

\section{Discussion}

Recent studies in psychotherapy have suggested the relevance of innovative moments (IMs) in the transformation of problematic self-narratives (Alves et al., 2012, in press; Gonçalves, Mendes et al., 2010; Matos et al., 2009; Mendes et al., 2010; Santos et al., 2009). In line with previous research, this study allowed us to explore how IMs are associated with self-reconstruction and symptomatic improvement in grief therapy. Our study also addressed how overall IMs were associated with themes identified in previous research as relevant narrative processes in grief adaptation (Alves et al., in press), such as loss integration and the search for moments of well-being and life reconstruction (i.e., proactivity).

In general, the results of this study reinforce the ability of the IMCS to capture the narrative changes involved in grief therapy, allowing for the study of how alternative interpretations of loss develop throughout successive sessions. The overall salience of IMs in this sample is $22.9 \%$, which means that a substantial proportion of the transcribed text includes IMs elaboration. This result is similar to the IMs' salience range found in other samples (e.g., CCT; Gonçalves et al., 2012; EFT, Mendes et al., 2010).

Regarding the pattern of overall IMs emergence, the results indicate that IM emergence is significantly predicted by time and by the interaction between time and symptomatic improvement. As presented in Figure 2, despite the similar probability of IMs occurrence at baseline, the differences between the cases start to become significant as time progresses, especially from session 6 onwards. More specifically, the rate of IMs production increases faster as treatment progressed in cases with greater symptomatic improvement. This finding is consistent with previous research indicating a higher rate of IM production over time in cases with greater symptomatic improvement, especially from the middle to the end of therapy (Gonçalves et al., 2012; Matos et al., 2009; Mendes et al., 2010). From our perspective, the higher rate of IM production in cases with greater clinical change supports the idea that narrative change co-occurs with therapeutic change. In grief therapy, specifically, the decreasing of complicated grief symptomatology may reflect the person's new ability to make sense and integrate the experience of loss in a more flexible and adaptive way 

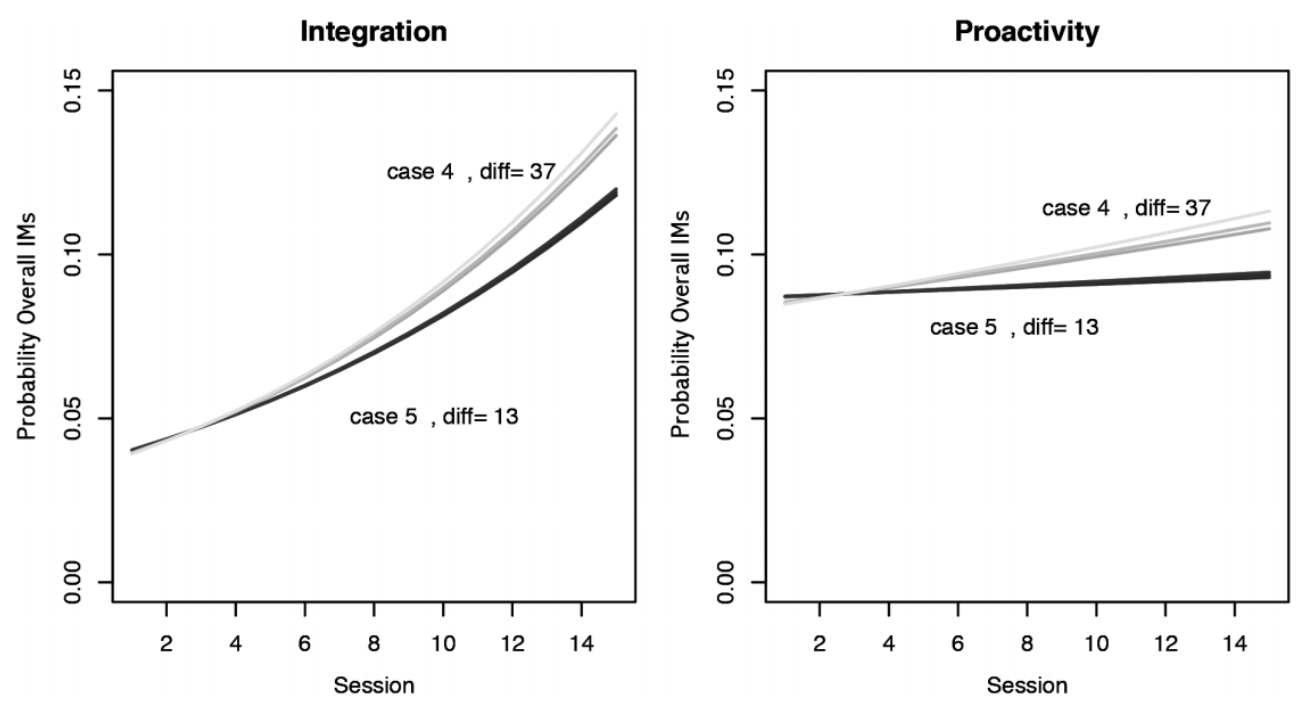

Figure 7. Integration and proactivity evolution in overall IMs. The different gradient lines represent the probabilities of integration and proactivity among cases with different pre to post differences in the ICG. Only the cases with extreme pre-post differences (4 and 5) are labeled in the figure.

(Alves et al., in press; Currier et al., 2007; Keesee et al., 2008; Lichtenthal et al., 2010; Neimeyer et al., 2006). In this sense, it seems that clients' progressive ability to invest in alternative experiences (IMs) and especially to integrate loss (Integration) and search for moments of well-being (Proactivity) is associated with more positive grief outcomes. The relevance of these processes is consistent with the model of Stroebe and Schut (1999), proposing the grief experience as a dynamic process in which the person actively organizes the meanings associated with the loss itself and struggles to rebuild a new reality of life in the aftermath of it.

The IMs with the lowest probability of emergence in this sample are action and protest, with probabilities lower than $1 \%$. These results are consistent with the lower salience of these IMs (less than $2 \%$ ) in previous studies in grief therapy according to the meaning reconstruction approach (Alves et al., 2012, in press). As suggested in both studies, the meaning reconstruction approach is much more oriented to the investment in new symbolic or representational ways of perceiving the loss and connecting with the lost person rather than through an emphasis on the expression of protest or behavioral processes to face the unwanted loss. In this sense, contrary to the presence of protest and action IMs observed in other cases (e.g., depression, women victims of partner violence), where the client actively engaged in new behaviors and new positions of criticism towards the problem's demands, the focus of the meaning reconstruction approach to grief therapy relies on more meaning-making interventions focused on clients' efforts to make sense of their new realities of life (Neimeyer, 2001, 2006b; Neimeyer et al., 2010).
Future studies with the IMCS are needed in order to further explore the role of these two specific IMs in this therapeutic modality. The higher salience of reflection and reconceptualization IMs (both meaning-centered IMs) in previous studies using the meaning reconstruction approach in grief therapy (Alves et al., 2012, in press) supports this hypothesis.

Performing change IMs have a maximum probability of occurrence of approximately $3.5 \%$ in this sample. Especially in the final part of therapy, the probability of this type of IM increases remarkably, but this increase is considerably more evident in cases with greater symptomatic improvement (Figure 6). The significant impact of the symptomatic improvement in performing change right from baseline - in contrast with the results for the other $\mathrm{IMs}$ - indicates that the elaboration of new projects and investments as a consequence of the change process (expressed through this IM) is more likely to happen in cases with less severe grief symptomatology. If we consider the hypothesis postulated by the heuristic model of change (Gonçalves et al., 2009) that performing change IMs represent clients' autonomous investment in a new life disconnected from the problematic self-narrative, this finding suggests that the elaboration of this specific IM in grief therapy is more likely to occur when the client is already capable of living the loss with lower levels of pain and suffering (that is, with less complicated grief symptomatology).

Reflection 1, reflection 2 and reconceptualization are the most salient IMs in the entire sample, especially reflection IMs, which represent $17.5 \%$ of the text coded as IMs. Reconceptualization represented only $3 \%$ of all the text coded as IMs, although 
it was the second most salient IM and had the highest probability of occurrence (25\%). Cases with different symptomatic evolutions differ significantly in the way they elaborate these IMs over time. While reflection 1 (Figure 3) decreases gradually over time, reflection 2 (Figure 4) increases gradually from the beginning until the end of treatment, especially in cases with higher symptomatic improvement. These results indicate that, as treatment progressed, clients moved from the description of their intentions to surpass the difficulties of complicated grief (reflection 1, creating distance from the problem) to the elaboration of new meanings and self-positions associated with a new and more flexible grief experience (reflection 2, centered on change). This progression over time was more remarkable in cases with greater symptomatic improvement. These results are consistent with previous studies that suggest that the evolution from reflection 1 to reflection 2 is an important change process, which is more pronounced in cases with greater symptomatic change (Mendes, Ribeiro, Angus, Greenberg, \& Gonçalves, 2011).

Reconceptualization is the IM that had the maximum probability of occurrence in this sample $(25 \%$ in the last session of case 4, as presented in Figure 5). As presented above, there is no significant effect of symptomatic improvement in reconceptualization probability. However, as time progresses, cases start to become significantly differentiated regarding the elaboration of reconceptualization. As illustrated in Figure 5, the probability of reconceptualization occurring is almost zero until the middle of therapy in all cases, and then it increases from session 6 onwards, especially in cases with greater symptomatic improvement. That is, cases with greater change present a higher rate of reconceptualization production compared with cases with lower change, which is more evident in the last sessions. This result seems to corroborate previous research suggesting the centrality of reconceptualization especially in later phases of successful therapy (Gonçalves et al., 2009), stressing the different profiles of IMs' evolutions among cases with different clinical progressions.

One of the main limitations of this study is the size of the sample, which constrains any attempt to generalize the conclusions to other complicated grief cases. However, we believe that this study supports the applicability of IMCS to different samples, supporting, at least partially, the heuristic model of change proposed by Gonçalves et al. (2009). Another limitation is the fact that all clients in this sample were followed by only one therapist in a non-manual intervention, which restricts data generalization.

Despite several limitations, this study may provide important information regarding the narrative processes involved in grief therapy and how these narrative constructions impact complicated grief recovery. In general, it suggests that therapists should focus on the promotion of meaning development as a central aspect in grief adaptation, with a special attention to the way clients understand the processes that have promoted their helpful changes.

Other particularities regarding the pattern of IMs of this study could also be considered for clinical practice. For example, the low proportion of protest IMs in this type of therapy may also orient the therapist toward a more reflective and integrative meaning reconstruction rather than the stimulation of a position of criticism regarding the problematic story of loss (which contrasts with the results from other studies in which the investment in protest IMs was central in clients' change; e.g., narrative change with victims of intimate violence). Obviously, more research is needed to confirm these findings.

\section{References}

Alves, D., Mendes, I., Gonçalves, M., Neimeyer, R. A. (2012). Innovative moments in grief therapy: Reconstructing meaning following perinatal death. Death Studies, 36, 795-818. doi:10. 1080/07481187.2011.608291

Alves, D., Fernández-Navarro, P., Ribeiro, A. P., Ribeiro, E., Gonçalves, M. (in press). Ambivalence and innovative moments in grief psychotherapy: The cases of Emily and Rose. Psychotherapy.

American Psychiatric Association (APA). (1994). Diagnostic and statistical manual of mental disorders (4th ed.). Washington DC: Author.

Angus, L., \& McLeod, J. (Eds.). (2004). The handbook of narrative psychotherapy: Practice, theory and research. London: Sage.

Angus, L., Levitt, H., \& Hardtke, K. (1999). The narrative processes coding system: Research applications and implications for psychotherapy practice. Fournal of Clinical Psychology, 55, 1255-1270. doi:10.1002/(SICI) 1097-4679(199910)55:10 $<1255:$ :AID-JCLP7>3.0.CO;2-F

Beck, A. T., Steer, R. A., \& Brown, G. K. (1996). Manual for Beck Depression Inventory II. San Antonio, TX: Psychological corporation.

Bonanno G. A., \& Mancini, A. D. (2006). Bereavement-related depression and PTSD: Evaluating interventions. In L. Barbanel \& R. J. Sternberg (Eds.), Psychological interventions in times of crisis (pp. 37-55). New York: Springer.

Braun, V., \& Clarke, V. (2006). Using thematic analysis in psychology. Qualitative Research in Psychology, 3(2), 77-101. doi:10.1191/1478088706qp063oa

Bruner, J. (1990). Acts of meaning. Cambridge, MA: Harvard University Press.

Bruner, J. (2004). The narrative creation of the self. In L. E. Angus \& J. McLeod (Eds.), The handbook of narrative psychotherapy: Practice, theory and research (pp. 3-14). London: Sage.

Coelho, R., Martins, A., \& Barros, H. (2002). Clinical profiles relating gender and depressive symptoms among adolescents ascertained by the Beck Depression Inventory II. European Psychiatry, 17, 222-226. doi:10.1016/S0924-9338(02)00663-6

Coleman, R. A., \& Neimeyer, R. A. (2010). Measuring meaning: Searching for and making sense of spousal loss in later life. Death Studies, 34, 804-834. doi:10.1080/07481181003761625 
Cunha, C., Gonçalves, M. M., Valsiner, J., Mendes, I. \& Ribeiro, A. P. (2012). Rehearsing renewal of identity: Reconceptualization on the move. In M. C. Bertau, M. M. Gonçalves \& P. Raggat (Eds.), Dialogic formations: Investigations into the origins and development of the dialogical self (series editor: Jaan Valsiner) (pp. 205-233). Charlotte, NC: IAP, Information Age Publications.

Currier, J. M., Holland, J. M., Coleman, R. A., \& Neimeyer, R. A. (2007). Bereavement following violent death: An assault on life and meaning. In R. Stevenson \& G. Cox (Eds.), Perspectives on violence and violent death (pp. 175-200). Amityville, NY: Baywood.

Del-Ben, C. M., Vilela, J. A. A., Crippa, J. A.de S., Hallak, J. E. C., Labate, C. M., \& Zuardi, A. W. (2001). Confiabilidade da «Entrevista Clínica Estruturada para o DSM-IV - Versão Clínica» traduzida para o português. Revista Brasileira de Psiquiatria, 23 (3), 156-159. doi:10.1590/S1516-444620010 00300008.

Dimaggio, G. (2006). Disorganized narratives in clinical practice. Fournal of Constructivist Psychology, 19, 103-108. doi:10.1080/ 10720530500508696

Field, N. P. (2006). Continuing bonds in adaptation to bereavement: Introduction. Death Studies, 30, 709-714. doi:10.1080/ 07481180600848090

First, M. B., Gibbon, M., Spitzer, R. L., Williams, J., \& Benjamin, L. (1997). Structured Clinical Interview for DSM-IV Axis II Personality Disorders: SCID-II. Washington DC: American Psychiatric Press.

First, M. B., Spitzer, R. L., Gibbon, M., \& Williams, J. B. W. (2002). Structured Clinical Interview for DSM-IV-TR Axis I Disorders, research version, non-patient edition (SCID-I/NP). New York: New York State Psychiatric Institute, Biometrics Research.

Frade, B., Rocha, J., Sousa, H., \& Pacheco, D. (2009). Validation of Portuguese version for Inventory of Complicated Grief. European Congress of Traumatic Stress, Oslo.

Gonçalves, M. M., Matos, M., \& Santos, A. (2009). Narrative therapy and the nature of "innovative moments" in the construction of change. Fournal of Constructivist Psychology, 22, 1-23. doi:10.1080/10720530802500748

Gonçalves, M. M., Mendes, I., Ribeiro, A., Angus, L., \& Greenberg, L. (2010). Innovative moments and change in emotion-focused therapy: The case of Lisa. Fournal of Constructivist Psychology, 23, 267-294. doi:10.1080/ 10720537.2010.489758

Gonçalves, M. M., Mendes, I., Cruz, G., Ribeiro, A., Angus, L., \& Greenberg, L. (2012). Innovative moments and change in client-centered therapy. Psychotherapy Research, 1-13. doi:10. 1080/10503307.2012.662605.

Gonçalves, M. M., \& Ribeiro, A. P. (2012). Therapeutic change, innovative moments and the reconceptualization of the self: A dialogical account. International fournal of Dialogical Science, 6, $81-98$.

Gonçalves, M. M., Ribeiro, A. P., Matos, M., Santos, A., \& Mendes, I. (2010). The Innovative Moments Coding System: A coding procedure for tracking changes in psychotherapy. In S. Salvatore, J. Valsiner, S. Strout, \& J. Clegg (Eds.), YIS: Yearbook of idiographic science 2009 (vol. 2, pp.107-130). Rome: Firera.

Gonçalves, M. M., Ribeiro, P. A., Mendes, I., Matos, M., \& Santos, A. (2011). Tracking novelties in psychotherapy process research: The Innovative Moments Coding System. Psychotherapy Research, 21, 497-509. doi:10.1080/10503307. 2011.560207

Gonçalves, M. M., \& Stiles, W. B. (2011). Introducing the special section on narrative and psychotherapy. Psychotherapy Research, 21, 1-3. doi:10.1080/10503307.2010.534510
Hill, C. E., \& Lambert, M. J. (2004). Methodological issues in studying psychotherapy processes and outcomes. In $\mathrm{M}$. J. Lambert (Ed.), Bergin and Garfield's handbook of psychotherapy and behaviour change (5th ed., pp. 84-135). New York: John Wiley \& Sons.

Jacobson, N. S., \& Truax, P. (1991). Clinical significance: A statistical approach to defining meaningful change in psychotherapy research. Fournal of Consulting and Clinical Psychology, 59, 12-19. doi:10.1037/0022-006X.59.1.12

Keesee, N. J., Currier, J. M., \& Neimeyer, R. A. (2008). Predictors of grief following the death of one's child: The contribution of finding meaning. Fournal of Clinical Psychology, 64, 1145-1163. doi:10.1002/jclp.20502

Lichtenthal, W. G., \& Cruess, D. G. (2010). Effects of directed written disclosure on grief and distress symptoms among bereaved individuals. Death Studies, 34(6), 475-499. doi: $10.1080 / 07481187.2010 .483332$

Lichtenthal, W. G., Currier, J. M., Neimeyer, R. A., \& Keesee, N. J. (2010). Sense and significance: A mixed methods examination of meaning-making following the loss of one's child. Fournal of Clinical Psychology, 66, 791-812.

Luborsky, L., Singer, B., \& Luborsky, L. (1975). Comparative studies of psychotherapies: Is it true that "Everyone has won and all must have prizes"? Archives of General Psychiatry, 32, 995-1008. doi:10.1001/archpsyc.1975.01760260059004

MacKinnon, C. J., Smith, N. G., Henry, M., Berish, M., Milman, E., Körner, A., ...Cohen, S. R. (2011). Development of a meaning-based group counselling intervention for bereavement: Preliminary results. Psycho-Oncology, 20(Suppl. 2), 85.

MacKinnon, C. J., Smith, N. G., Henry, M., Milman, E., Berish, M., Farrace, A., ...Cohen, S. R. (2012, October). A pilot randomized controlled trial of the meaning-based group counselling intervention. Proffered paper to be presented at the 19th International Congress on Palliative Care, Montreal, QC.

Matos, M., Santos, A., Gonçalves, M. M., \& Martins, C. (2009). Innovative moments and change in narrative therapy. Psychotherapy Research, 19, 68-80. doi:10.1080/10503300 802430657

McAdams, D. P. (2001). The psychology of life stories. Review of General Psychology, 5, 100-122. doi:10.1037/1089-2680.5.2.100

McDevitt-Murphy, M. E., Neimeyer, R. A., Burke, L. A., Williams, J. L., \& Lawson, K. (2012). The toll of traumatic loss in African Americans bereaved by homicide. Psychological Trauma: Theory, Research, Practice, and Policy, 4, 303-311.

Mendes, I., Ribeiro, A. P., Angus, L., Greenberg, L., \& Gonçalves, M. M. (2011). Narrative change in emotionfocused psychotherapy: A study on the evolution of reflection and protest innovative moments. Psychotherapy Research, 21, 304-315. doi:10.1080/10503307.2011.565489

Mendes, I., Ribeiro, A. P., Angus, L., Greenberg, L. S., Sousa, I., \& Gonçalves, M. M. (2010). Narrative change in emotionfocused therapy: How is change constructed through the lens of the Innovative Moments Coding System? Psychotherapy Research, 20, 692-701. doi:10.1080/10503307.2010.514960

Neimeyer, R. A. (2001). Meaning reconstruction and the experience of loss. Washington DC: American Psychological Association.

Neimeyer, R. A. (2006a). Complicated grief and the quest for meaning: A constructivist contribution. Omega, 52, 37-52.

Neimeyer, R. A. (2006b). Lessons of loss: A guide to coping. Memphis, TN: Center for the Study of Loss and Transition.

Neimeyer, R. A. (2009). Constructivist psychotherapy. New York: Routledge.

Neimeyer, R. A., Baldwin, S., \& Gillies, J. (2006). Continuing bonds and reconstructing meaning: Mitigating complications in bereavement. Death Studies, 30, 715-738. doi:10.1080/ 07481180600848322 
Neimeyer, R. A., Burke, L. A., Mackay, M. M., \& van DykeStringer, J. G. (2010). Grief therapy and the reconstruction of meaning: From principles to practice. Fournal of Contemporary Psychotherapy, 40, 73-83. doi:10.1007/s10879-009-9135-3.

Neimeyer, R. A., Herrero, O., \& Botella, L. (2006). Chaos to coherence: Psychotherapeutic integration of traumatic loss. Fournal of Constructivist Psychology, 19, 127-145. doi:10.1080/ 10720530500508738

Neimeyer, R. A., \& Levitt, H. (2001). Coping and coherence: A narrative perspective on resilience. In R. Snyder (Ed.), Coping with stress (pp. 47-67). New York: Oxford University Press.

Polkinghorne, D. E. (2004). Narrative therapy and postmodernism. In L. E. Angus \& J. McLeod (Eds.), The handbook of narrative and psychotherapy: Practice, theory and research (pp. 53-68). Thousand Oaks: Sage.

Prigerson, H. G., Horowitz, M. J., Jacobs, S. C., Parkes, C. M., Aslan, M., Goodkin, K., ...Maciejewski, P. K. (2009). Prolonged grief disorder: Psychometric validation of criteria proposed for DSM-V and ICD-11. PLoS Medicine, 8, 1-12.

Prigerson, H., \& Maciejewski, P. (2006). A call for sound empirical testing and evaluation of criteria for complicated grief proposed for the DSM-V. Omega, 52, 9-19.

Prigerson, H. G., Maciejewski, P. K., Reynolds, C.F. III, Bierhals, A. J., Newsom, J. T., Fasiczka, A., ... Miller, M. (1995). Inventory of Complicated Grief: A scale to measure maladaptive symptoms of loss. Psychiatry Research, 59, 65-79. doi:10. 1016/0165-1781(95)02757-2

Ribeiro, A., Bento, T., Salgado, J., Stiles, W. B., \& Gonçalves, M. M. (2011). A dynamic look at narrative change in psychotherapy: A case study tracking innovative moments and protonarratives using state space grids. Psychotherapy Research, 21(1), 54-69. doi:10.1080/10503307.2010.504241

Ribeiro, A. P., Gonçalves, M. M., \& Ribeiro, E. (2009). Processos narrativos de mudança em psicoterapia: Estudo de um caso de sucesso de terapia construtivista [Narrative processes of change in psychotherapy: A good outcome case of constructivist therapy]. Psychologica, 50, 181-203.

Santos, A., Gonçalves, M. M., \& Matos, M. (2011). Innovative moments and poor outcome in narrative therapy. Counselling
Psychotherapy and Research, 11, 129-139. doi:10.1080/147331 40903398153

Santos, A., Gonçalves, M., Matos, M., \& Salvatore, S. (2009). Innovative moments and change pathways: A good outcome case of narrative therapy. Psychology and Psychotherapy: Theory, Research and Practice, 82, 449-466. doi:10.1348/14760 8309X462442

Sarbin, T. R. (1986). The narrative and the root metaphor for psychology. In T. R. Sarbin (Ed.), Narrative psychology: The storied nature of human conduct (pp. 3-21). New York: Praeger.

Seggar, L. B., Lambert, M. J., \& Hansen, N. B. (2002). Assessing clinical significance: application to the Beck Depression Inventory. Behavior Therapy, 33(2), 253-269. doi:10.1016/ S0005-7894(02)80028-4

Shear, K., Boelen, P., \& Neimeyer, R. A. (2011). Treating complicated grief: Converging approaches. In R. A. Neimeyer, D. Harris, H. Winokuer \& G. Thornton (Eds.), Grief and bereavement in contemporary society: Bridging research and practice (pp. 139-162). New York: Routledge.

Sousa, V., \& Rocha, J. C. (2011). Validação de metodologias de diferenciação clinica entre luto saudável e luto complicado (Unpublished master's thesis). Instituto Superior de Ciências da Saúde do Norte, Gandra, Portugal.

Steer, R. A., Brown, G. K., Beck, A. T., \& Sanderson, W. C. (2001). Mean Beck Depression Inventory-II scores by severity of major depressive episode. Psychological Reports, 88(3c), 1075-1076.

Stroebe, M., \& Schut, H. (1999). The dual process model of coping with bereavement: Rationale and description. Death Studies, 23, 197-224.

Weertman, A., ArntZ, A., Dreessen, L., Velzen, C.van, \& Vertommen, S. (2003). Short-interval test-retest interrater reliability of the Dutch version of the Structured Clinical Interview for DSM-IV Personality Disorders (SCID-II). Fournal of Personality Disorders, 17(6), 562-567.

White, M. (2007). Maps of narrative practice. New York, NY: Norton.

White, M., \& Epston, D. (1990). Narrative means to therapeutic ends. New York: Norton. 